\title{
Arbor
}

\section{El hispanismo francés y la España contemporánea (historia y literatura)}

\section{Carlos Serrano}

Arbor CLXVIII, 664 (Abril 2001), 563-574 pp.

La difusión del castellano como segunda lengua extranjera más enseñada - después del inglés- en la educación secundaria francesa ha tenido evidentes efectos para el mundo académico. El interés por el castellano ha conllevado, en efecto, la ampliación de un ingente cupo de estudiantes a las correspondientes Universidades. Estas, a su vez, por su dinámica propia, se han ido multiplicando a lo largo y a lo ancho del país en los últimos años, con sus correspondientes departamentos de español, de tal modo que se ha ido formando un densa red de hispanistas (estudiantes y profesores dedicados a temas españoles y/o iberoamericanos) universitarios en Francia, cuya contribución al conocimiento de la historia, de la literatura y de la lengua españolas es, sin embargo, un tanto variopinto.

Por una particularidad propiamente francesa, los departamentos referidos a «lenguas» de las Universidades se sitúan al margen de la tradición meramente filológica que les llevaba a no interesarse más que a los campos de lengua y literatura. En la actualidad, están abiertos también al amplio campo de lo que se ha venido llamando la «civilización», de contenido variable pero que en todo caso apunta hacia temas muy diversos, que pueden aproximarse a múltiples aspectos de la cultura española, pero también a las varias ramas de las ciencias humanas y sociales. A todo ello, conviene añadir que en los últimos años se han abierto numerosas carreras denominadas de «lenguas extranjeras aplicadas», en las que se juntan asignaturas de dos o tres lenguas, con otras de economía y de derecho, etc., con vistas a la preparación de diplomas para funciones del sector de servicios, como comercio internacional, gestión, etc., de modo que puede decirse que, al menos de forma potencial, casi todos los aspectos de la sociedad española pueden tener cabida en la fomación en las di- 
versas modalidades de la formación universitaria francesa, ora en los propios departamentos de «estudios ibéricos», «hispánicos», o como se llamen, ora en sus equivalentes de historia, derecho, arquelogía, historia del arte, literatura comparada, etc.

A esta omnímoda presencia virtual del español y de una materia hispánica en la enseñanza para un alumnado bastante abundante pero de no siempre un nivel académico elevado, corresponden unos resultados más modestos en el campo de la investigación y de la producción científica francesa en todo lo relativo a España. La acaparación por las labores docentes o administrativas de muchas de las energías de estos profesores-investigadores universitarios reduce notablemente su dedicación a la investigación, que en no pocas ocasiones es pura y sencillamante sustituida por trabajos o publicaciones pedagógicas, de indudables méritos en su campo pero que poco tienen que ver con lo que aquí se trata. Por otra parte, y paradójicamente, la multiplicación de centros de estudios hispánicos que se han ido creando en las diversas universidades, viejas y nuevas, ha contribuido también a una relativa fragmentación de la investigación, y ha favorecido una inevitable tendencia al localismo: cada centro, para justificar su existencia, tiene que hacer aparecer una faceta de investigación, que se materializa en la organización de algún encuentro o coloquio cuyo tema se define entonces más por su relación con los centros de interés personales de los organizadores, federados un poco a la fuerza, que por una real coherencia científica. Luego se publican las actas, para dar constancia del trabajo realizado, por el correspondiente centro de publicaciones local, cuya difusión permanece semi-clandestina. $\mathrm{Al}$ fin, se puede llegar a una inversión completa de objetivos, que hace que se acabe investigando para publicar (justificativo de ayudas y presupuestos), en vez de ir publicando los resultados de una verdadera investigación...

Con todo, y a pesar de estas reales dificultades, el panorama general no es tan sombrío como estas palabras liminares podrían darlo a entender. Las investigaciones francesas en el campo o en los campos relativos a la España contemporánea han producido y siguen produciendo obras abundantes y de calidad, en terrenos muy diversos, que hacen su riqueza. Algunos autores, de consolidado prestigio, han seguido dando a la imprenta diversas y notables obras de recopilación algunas, de síntesis otras. En este orden de ideas, conviene señalar el ejemplo de Pierre Vilar, con una importante miscelánea de trabajos dispersos (Nation, nationalisme et questions nationales, Paris, Ibérica $\mathrm{n}^{\text {lle }}$ série, $\left.\mathrm{n}^{\circ} 4,1994\right)$; el de Bartolomé Bennassar con el amplio panorama de una Historia de los españoles enfocada más desde lo cotidiano y las formás de vida que de la 
política o de la economía; o el de Joseph Perez, con su reciente Historia de España, que, a pesar de ser más especialista de los siglos XV y XVI, se atreve a ofrecer una visión de conjunto de su materia, con propuestas innovadoras incluso para épocas más modernas. Con un objetivo más limitado, algo parecido se propuso con éxito el librito de Bernard Vincent sobre el Descubrimiento y sus prolongaciones en España hasta el siglo XX, (1492, «l'année admirable», París 1991). Es revelador que muchos de estos autores más conocidos como especialistas de una época más remota, hayan sentido la necesidad de acercarse al presente en estas obras, cosa que por lo demás B. Bennassar repitió con dos o tres libros más, y en particular una tentativa de biografía de Franco (París, 1995), que vino a competir en un mercado ya bien abastecido en este tema, y al que salió también la obra de la hispanista Andrée Bachoud, Franco ou la réussite d'un homme ordinaire (París, 1997). A todo ello podría añadirse el conjunto de trabajos relativos al franquismo, la retórica imperial y la lógica militar analizadas por Pilar Martínez Vasseur por un lado (Pouvoir absolu et monarchie militaire en Espagne, Nantes, 1989) y por Marie Aline Barrachina, por otro (Propagande et culture dans l'Espagne franquiste, 1936-1945, Grenoble, 1998).

Indudablemente, la salida del franquismo, la transición, la posterior consolidación de la democracia y la incorporación de España a una Europa unificada, han suscitado un nuevo interés bibliográfico entre autores que no estaban necesariamente vinculados tradicionalmente al campo del hispanismo: historiadores, politólogos, economistas..., se han acercado al «caso» español, desde ángulos muy diversos, desde el constitucionalismo (D.C. Lavroff, Le régime politique espagnol, Paris, 1985; Dix ans de démocratie, La Documentation française, 1986...), hasta la historia política, en la que Guy Hermet ha proseguido una obra iniciada hace tiempo y prolongada hoy por Francisco Campuzano, con L'élite franquiste et la sortie de la dictature (París, 1997) o Sylvia Desazars de Montgaillard, con un muy documentado trabajo sobre la transición y, en particular, el papel de la antigua U.C.D. (Toulouse, 1995). El campo de la economía no ha quedado al margen de este proceso, examinado a traves del prisma geográfico (Alain Huetz de Lemps), de su desarrollo territorial (Michel Drain y en particular la cuestión del agua) o de una visión más sintética, con la Historia económica de España (París, 1998) presentada por Albert Broder, al tiempo que Gérard Chastagnaret anuncia la publicación de sus trabajos sobre la minería española. Estos dos últimos autores, con Emile Témime, han sido por otra parte los autores de un panorama completo de la historia española de la época contemporánea que ha sido un éxito en Francia, Histoire de l'Espagne contemporai- 
ne (París, 1988), traducida ulteriormente al castellano. También han surgido algunas obras dedicadas más especificamente a la España contemporánea, a la que el autor se acerca desde un ángulo particular, como es el caso de F. Lafage, L'Espagne de la contre-révolution. Développement et déclin, XVIII-XX siècles (París, 1993) o, en cierto modo, el reciente volumen antológico de Vicente Garmendia Jaungoicoa eta forua. El carlismo vasconavarro frente a la democracia española, 1868-1872, (Bilbao, 1999) y la tesis reciente de Jean Marc Delaunay, sobre las relaciones hispano-francesas a principios del siglo XX, de próxima publicación. Por su parte, la «España del siglo XX», ha sido objeto de diversas publicaciones, generalmente con ese mismo título, en diferentes colecciones académicas y por variados autores (G. Hermet, (París, 1989), J. Maurice/C. Serrano (París, 1992), M. T. Pérez Picazo/G. Lemeunier (París, 1994), alguna de las cuales ha logrado varias reediciones, prueba de que este tipo de síntesis responde efectivamente a una necesidad del mercado universitario. Por otra parte, al fin, las clásicas colecciones de difusión más amplia y orientadas hacia un público menos especializado, como la colección «128» de Nathan o la colección «Que sais-je?» de le editorial PUF, han seguido incluyendo ocasionalmente volúmenes relativos al ámbito español, como los dos que Michel y Marie Claire Zimmermann han dedicado a la historia y a la literatura catalana, el Madeleine y Arcadio Prado sobre la métrica española o el de Anne Dulphy sobre la historia de España desde 1808 hasta hoy, los de Bernard Bessière sobre la cultura española después de 1975 o el de Jean Claude Seguin sobre la historia del cine español. Pero en estos últimos años un fenómeno nuevo parece haber surgido, al calor de una peculiaridad del actual mercado editorial de la materia hispánica, en su versión académica. Los concursos de oposiciones a cátedras de la enseñanza secundaria, organizada en Francia a escala nacional con un programa también nacional de obras que son explicadas en las Universidades, han hecho surgir unas editoriales que se han especializado en este mercado más o menos captivo, publicando unos vólumenes pensados y realizados en pocos meses para responder a la supuesta demanda angustiada de los opositores con una información de urgencia, y cuyos resultados resultan a veces discutibles y, en todo caso, muy desiguales, a veces en detrimento de posibles publicaciones de calidad en editoriales profesionales. A la inversa, el interés por el mundo hispánico ha tenido como efecto cierta popularización en Francia de la literatura, y en particular de la novelística, española, acogida en casi todas las grandes editoriales. En esta difusión de la literatura española, los universitarios hispanistas desempeñan un papel notable, las más veces como traductores de las obras de los escritores españoles contem- 
El hispanismo francés y la España contemporánea (historia...

poráneos: en este caso, la Universidad parece cumplir con una de sus funciones de divulgación, para un público de no especialistas, de una materia especializada. Como también ha ocurrido en un campo vecino como es el de la preparación de historias de la literatura española, que, como no podía ser menos, ha sido y sigue siendo un objeto privilegiado en unos departamentos universitarios entre cuyos principales objetivos figura el estudio de esa asignatura. Además de algunos manuales de iniciación o de someros panoramas para alumnos de secundaria, dos obras recientes parecen haber sido relevantes en este campo: con la primera, Robert Jammes y Jacques Beyrie han ofrecido una útil introducción para público universitario con su sintética Histoire de la littérature espagnole (París, 1994). Por su parte, Jean Canavaggio ha reunido la plana mayor del hispanismo francés para llevar a cabo otro proyecto de idéntico título (París, 1993-1994 y posteriormente traducida al castellano), pero de mucho mayor extensión y con la ambición de producir una obra de referencia para todo género de públicos, ya sea especialista ya sea sencillamente culto y en busca de informaciones.

$\mathrm{Al}$ margen de estas grandes síntesis o, al contrario, de los manuales de iniciación, permanecen vivas algunas grandes líneas de investigación y de publicación. Sigue existiendo en Francia una sólida escuela de historiadores dedicados a la época de la Ilustración, de la guerra de la Independencia y de los primeros tiempos del liberalismo. Al margen de alguna que otra tesis aún inédita, Claude Morange (editor de Sebastián de Miñano, Sátiras y panfletos del trienio constitucional, Madrid, 1994 y autor de Siete calas en la crisis del Antiguo Régimen español, Alicante, 1990, entre otros trabajos), Gérard Dufour (especialista desde años en LLorente, pero también en el clero, en la inquisición y en las ideologías de finales del siglo XVIII)), Françoise Etienvre (autora entre otras cosas de una estupenda edición de Capmany, Centinela contra franceses, Londres, 1988), Jean René Aymes (que tras haberse durante años dedicado a los españoles en Francia, y al impacto de la Revolución francesa en España (en tanto que editor de las actas del coloquio España y la revolución francesa, Barcelona, 1989 y de La guerra de España contra la revolución francesa, 1793-1795, Alicante, 1991), ha trabajado ultimamente sobre las «imágenes» que residentes de uno y otro país se han ido formando recíprocamente, como lo atestiguan las actas de un coloquio que publica con J. Fernández Sebastián (L'Image de la France en Espagne (1808-1850), París/Bilbao, 1997). En un mismo orden de ideas, todo parece indicar que este mismo siglo XIX incipiente ha llamado la atención de los editores, que han aceptado ofertas de ediciones o reediciones de toda una literatura testimonial (Custine, L'Espagne de Ferdinand VII, París,1991) y de 
viajeros (J.R. Aymes, Aragón y los románticos franceses, 1830-1860, Zaragoza, 1986); B. y L. Bennassar, Le voyage en Espagne. Anthologie des voyageurs français et francophones du XVIe au XXe siècle (París, 1998). La era romántica, un poco dejada de lado ultimamente por los especialistas, ha permitido sin embargo la aparición de alguna obra fundamental, como el José de Espronceda de Robert Marrast (París, 1974, pero recientemente traducido al castellano) o de algún trabajo de menores ambiciones de Jean Louis Picoche en torno a Zorrilla o Hartzenbusch, mientras que una obra colectiva, co-dirigida por A. Derozier y A. Gil Novales, reivindicaba a Larra (Revisión de Larra (¿Protesta o revolución?, París, 1983). Desde una perspectiva muy diferente, también han versado sobre la primera mitad del siglo XIX un coloquio reciente organizado conjuntamente por Jean Louis Guereña, de la Universidad de Tours, y A. Viñao Fraga, en el que se examinaba el proceso de escolarización en la España (Estadísticas escolares, proceso de escolarización y sistema educactivo nacional en España, 1780-1850, Barcelona, 1996), que ha venido a prolongar otros varios encuentros y publicaciones de calidad sobre temas vecinos pero en fechas diversas, que se vienen llevando a cabo desde la Universidad de Tours.

La segunda mitad del siglo XIX ha conocido un tratamiento muy dispar. Si el período isabelino sigue sufriendo de un relativo abandono y el sexenio no ha sido objeto de revisión historiográfica importante reciente, el período de la Restauración, de la crisis finisecular y de la edad de pla$t a$ han seguido siendo objeto predilecto de muchos hispanistas, favorecidos además por los azares del calendario. La Universidad de Toulouse, en particular, ha sido el centro organizador de varios coloquios notables, sobre Realismo y naturalismo en España (Barcelona, 1988) uno, sobre Pensamiento y literatura en España en el siglo XIX. Idealismo, positivismo, espiritualismo otro (Toulouse, 1998), en los que ha desempeñado un papel determinante la gran erudición y la capacidad de convocatoria de Yvan Lissorgues. Paralelamente, el interés por algunos de los grandes novelistas decimonónicos ha seguido alto, con varias contribuciones en torno a Clarín (cuya Regenta ha sido objeto de una primera traducción al francés por un grupo de hispanistras franceses en 1987) y Pérez Galdós, al que Sadi Lakhdari ha dedicado un estudio enfocado desde los postulados psicoanalíticos ("Angel Guerra» de B. Pérez Galdós, París, 1996). En la misma época, la Universidad de Parix X, bajo el impulso de Jacques Maurice y de sus colaboradores, organizaron une serie de seminarios y un encuentro sobre Le roman espagnol au XXe siècle (París, 1997) y un coloquio "centenario» sobre 1898: entre literatura e historia (Crisol, $\mathrm{n}^{\circ} 2$, París, 1999). Al margen de operaciones como éstas, que requieren es- 
fuerzos organizativos, medios económicos y apoyos institucionales, las diversas revistas especializadas han ido publicando regularmente las contribuciones de unos y de otros sobre los autores faros del primer tercio del siglo XX, de Antonio Machado a Federico García Lorca (objeto de múltiples trabajos académicos y editoriales, de parte de Michèle Ramond en particular, en una óptica crítica marcada por las influencias psicoanalíticas y el inconsciente (La question de l'autre dans Federico García Lorca, París, 1999), Miguel Hernández (con un coloquio co-organizado por S. Salaün y J. Pérez Bazo (Alicante, 1996), pero con una atención más particular puesta en Ramón del Valle Inclán, al que desde la Universidad de Dijon, Jean Marie y Eliane Lavaud han dedicado sus tesis, ya clásicas, sobre respectivamente la prosa y el teatro del autor gallego, pero además un libro de presentación del autor y de su obra para el público francés (Valle Inclán: un Espagnol de la rupture, Arles, 1991). Por otra parte, el centro de investigación que estos dos especialistas animan ha organizado un coloquio especializado sobre las Comedias bárbaras, del mismo autor, cuyas actas se han publicado en su momento (Dijon, 1996). Autores u obras menos considerados hoy también han sido objeto de varios trabajos académicos, como los de Edouard Samper sobre Etchegaray, de Christine Rivalan Guégo, sobre le novela erótica de principios de siglo (Frissons, fictions. Romans et nouvelles en Espagne, 1894-1936, Rennes, 1998), de Christian Manso sobre Azorín, etc. En este repaso, necesariamente supeficial, cabe señalar la existencia de un sector académico de los departamentos de español dedicado a los estudios catalanistas, con algunos puntos fuertes en Perpignan, Aix en Provence y, en particular, en París, con el Centre d'Etudes catalanes. A estos núcleos de especialistas se deben estudios relevantes, tesis o libros sobre Ausias March (M.C. Zimmermann), Salvador Espriu (Denise Boyer) o incluso Aribau (Antoni Lluc Ferrer, La patrie imaginaire. La projection de «La Patrie» de B.C. Aribau (1832) dans la mentalité catalane contemporaine, Aix en Provence, 1987), así como varios coloquios, como el dedicado a Santiago Rusiñol (París, 1994).

La segunda República y la guerra civil tampoco han dejado de ser temas más o menos recurrentes en la bibliografía de los hispanistas franceses. Al margen de publicaciones especilizadas (Le Mouvement social por ejemplo), algunos historiadores han procurado confirmar sus tesis, pero en base a una documentación parcialmente renovada (Pierre Broué, Staline et la révolution: le cas espagnol (1936-1939), París, 1993), otros han buscado hacer un balance de lo que fue el acontecimiento y de su propia aportación a su historiografía (Pierre Vilar, La Guerre d'Espagne, París, 1986; o Emile Témime (Bruxelles, 1996), Guy Hermet, (París, 
1989); otros se han dedicado al examen de algún punto particular (Carlos Serrano, L'enjeu espagnol. PCF et guerre d'Espagne, París, 1987; Yveline Riottot (Joaquín Maurín: de l'anarcho-syndicalisme au communisme, París, 1997); o el joven historiador Rémy Skoutelsky, sobre los voluntarios franceses de las brigadas internacionales (L'espoir guidait leurs pas. Les volontaires français dans les Brigades Internationakles, 1936-1939, París, 1998), mientras diversos coloquios abordaban diversas facetas de la guerra (Papy, Pau, 1999), de los debates ideológicos que le son contemporáneos (Wolikow, Dijon 1998), o, más sistemáticamente, de la emigración que resulta del mismo (en torno a la BDIC con Dreyfus-Armand a su cabeza y con A. Bachoud o los trabajos de Rose Duroux en Clermont-Ferrand). Al calor de estos primeros trabajos, también empiezan a desarrollarse, en colaboración con investigadores españoles, trabajos sobre la literatura del exilio.

Una línea innovadora de investigación, en la que participan investigadores de origen diverso ha sido la que se viene desarrollando en torno a la cuestión del libro y de la lectura en España. Las diferentes entregas recientes (1998-1999) del siempre cuidado Bulletin Hispanique (de Burdeos), capitaneados por François Lopez, han dado abundante prueba de lo fructífero de este renovado campo de trabajo, en el que se juntan por igual especialistas del Siglo de Oro, de la Ilustración y de la época contemporánea. Para ésta, Jean François Botrel, con La diffusion du livre en Espagne (1868-1914) (París/Madrid, 1988) y Libros, prensa y lectura en la España del siglo XIX (Madrid, 1993), ha sido pionero, contribuyendo ampliamente al descubrimiento de un territorio casi virgen hasta la fecha: desde las modalidades de la lectura hasta el folletín, del ciego como medium hasta las memorias de editores o impresores, todo un mundo, esencial en la comprensión de cómo se ha ido formando el mundo mental y cultural de los españoles, de este modo va surgiendo del olvido. En esta misma línea, pero en la perpectiva de establecer una visión de conjunto de la historia de un verdadero género literario-editorial, Geneviève Champeau (autora por otra parte de un importante Les enjeux du réalisme dans le roman sous le franquisme, París/Madrid, 1993) y Nadine Ly (especialista de teoría literaria y del análisis textual en una orientación de «literalidad»), acaban de coordinar la publicación de un excelente trabajo sobre Le phénomène anthologique dans le monde ibérique contemporain (Bordeaux, 2000), que permite útiles reflexiones tanto sobre el mercado como sobre la producción literaria más o menos institucionalizada. Por su parte, Philippe Castellano, con una obra sobre la enciclopedia Espasa Calpe, Robert Coale, con un estudio sobre los premios literarios, Anne Lenquette, en una aproximación al mundo editorial de la novela 
contemporánea, contribuyen con sus respectivas tesis y cada uno a su modo a estos planteamientos, intermediarios entre el campo de la literatura, propiamente dicha, y de la historia literaria.

En un terreno vecino, aunque en busca de un horizonte más amplio, se está desarrollando en Francia un sector de investigación que se define a sí mismo por referencia a una «historia cultural», cuyos márgenes no siempre están bien definidos. Evidentemente, este sector tiene modelos intelectuales que le vienen de la historiografía propiamente francesa (Chartier, Ory, Sirinelli, etc.), pero entra también en contacto con cierta forma de entender los anglosajones sus «cultural studies» cuando éstos no son mero etnicismo más o menos disfrazado. Utilizando el aporte de los sectores antes evocados, pero buscando situarlos en un contexto más amplio y sobre todo en el entramado de sus interrelaciones, estos estudios de «historia cultural» han ofrecido una primera aproximación colectiva con la obra 1900 en Espagne (Burdeos, 1988, posteriormente traducida al castellano, Madrid, 1991), que sistematizaba una reflexión en torno a una fecha decisiva aunque polémica (1900 vs 1898), con la voluntad de resaltar las dinámicas del momento, más que la singularidad de tal o cual obra particular. Desde entonces, por lo menos otros dos proyectos colectivos están en marcha, que deberían aparecer en un futuro no demasiado lejano, coordinado uno por J.R. Aymes (sobre el siglo XIX), por S. Salaün, E. Trenc y C. Serrano otro (sobre los años 1920). Entre tanto, han ido apareciendo diversas obras más monográficas, pero de calidad y que demuestran el interés de este tipo de enfoque globalizador, como el 1900 en Salamanca de Jean Claude Rabaté (Salamanca, 1997) o, en otra perspectiva muy diferente, el trabajo coordinado por Brigitte Magnien, Hacia una literatura del pueblo: del folletín a la novela, Barcelona, 1995). A esa misma línea de recuperación de unos fenómenos culturales olvidados o dejados de lado petenece también la antología de C. Serrano, Carnaval en noviembre. Parodias teatrales españolas de «Don Juah Tenorio», (Alicante, 1996).

En el cruce de la historia cultural, de los planteamientos sobre representaciones e imaginarios políticos y sociales, el hispanismo francés lato sensu ha ofrecido ya unas tesis de gran interés, alguna de la cual está también a punto de publicarse en España: Pierre Géal, sobre la formación del museo de arte en España, Stéphane Michonneau, sobre los «lugares de la memoria» en Barcelona y Christian Demange, sobre la tradición del 2 de mayo en Madrid. Dos volúmenes coordinados por C. Serrano, han recogido trabajos colectivos en este campo de un coloquio obre «Imaginaires et symboliques dans l'Espagne franquiste», (número extraodinario del Bulletin d'histoire contemporaine de l'Espagne 
Bordeaux, 1996) y de un seminario (Nations en quête de passé, París, 2000). A medio camino entre historia literaria, historia del espectáculo e historia cultural, Serge Salaün, por su parte, tras su conocido libro sobre El Cuplé (Madrid, 1990), ha dado a la imprenta diversos trabajos sobre «El paralelo» de Barcelona, el teatro comercial, etc., que giran en torno a temas vecinos. Estas diversas investigaciones sobre el teatro de principios de siglo le han llevado paralelamente a la edición crítica y abundantemente prologada del «teatro de ensueño» de Gregorio Martínez Sierra, acompañada por la traducción que éste hizo en su momento, de $L a$ Intrusa de Maeterlinck (Madrid, 1999). Por supuesto, estas corrientes críticas no son para nada exclusivas, y los diversos investigadores de los muchos departamentos de estudios hispánicos de Francia han producido una abundante bibliografía sobre obras y autores contemporáneos, excesivamente numerosos para poderlos reseñar todos aquí. En Grenoble o en Montpellier, en perspectivas narratológicas o de socio-crítica, G. Tyras, J. F. Carcelen, otros más, se han dedicado a Vázquez Montalbán, J.J. Millás, a Juan Goytisolo, como Annie Bussière-Perrin (La théâtre de l'expiation: regards sur l'œuvre de rupture de Juan Goytisolo, Montpellier, 1998) quien, prolongando trabajos anteriores en los que Jean Tena había asumido un papel determinante, ha obrado de coordinadora de un volumen ambicioso, Le roman espagnol actuel. Tendances et perpectivas, t.1, Montpellier, 2000). En París, J.P. Ressot ha continuado su exploración estilística de la obra de Ramón Sender, mientras que su inclusión en los programas de oposición ha favorecido cierto interés crítico renovado por Juan Benet (E. Lavaud (ed.), Juan Benet: ensayos (Dijon 1995); Claude Murcia (Juan Benet: dans la pénombre de Région, París, 1998), al que han acompañado por otra parte diversas traducciones, generalmente de la mano de la misma Claude Murcia, en las parísinas Editions de Minuit. Teatro y poesía contemporáneos no han quedado totalmente marginados, y en Toulouse (Monique Hernandez, Valle Inclán, père mythique, Toulouse, 1993), París (S. Salaün, M.C. Zimmermann...), Rennes, ClermontFerrand (con E. Martín- Hernández y, en particular, sus trabajos sobre Blas de Otero) y otros centros han favorecido la preparación de tesis, libros y traducciones de poetas (Siles, ...), acaso más que de dramaturgos contemporáneos.

Paralelamente a los temas tradicionales en los departamenos de filología, se han ido desarrollando nuevos sectores de investigación, con resultados ya bastante consolidados: la prensa, que ha sido objeto de espléndidas publicaciones monográficas, como el libro de Solange HibbsLissorgues, Iglesia, prensa y sociedad en España (1868-1904), Alicante, 1995), así como de tesis (como la de Gérard Imbert sobre «las estrategias 
de cambio en el discurso social de la transición española», París, 1991) y artículos derivados como los de Florence Belmonte, Marie Claude Chaput, Marie Franco, etc. En torno a la historia de la prensa, se ha constituido por lo demás una red interuniversitaria, con sede en Burdeos y en la persona de Jean Michel Desvois («PILAR»), que difunde por internet sus informaciones, pero también organiza sus coloquios anuales, con las correspondientes actas. Paralelamente, los especialistas de otros media, en particular del cine, se han multiplicado, con una fuerte presencia en diversos departamentos y algunos excelentes resultados: en particular Emmanuel Larraz en Dijon, Jean Claude Seguin en Lyon, con sendas introducciones a la historia del cine español, o Nancy Berthier en París, han publicado recientemente tanto obras de síntesis, actas de coloquios (Voir et lire García Berlanga. El Verdugo, Dijon, 1998), como estudios monográficos (sobre Le Franquisme et son image, Toulouse, 1998, referido a Raza y al cine de Saenz de Heredia, o De la guerre à l'écran: «iAy Carmela! de Carlos Saura, Toulouse, 1999). Por su parte, el turismo tampoco ha quedado al margen de estos desarrollos recientes del hispanismo francés, con los trabajos de Hervé Poutet (Images touristiques de l'Espagne, París, 1995) o la tesis de Alet Valero («Pratiques, images et politique touristique en Espagne, 1830-1928», Aix en Provence, 1993). La historia del arte, en el sentido más clásico de esta expresión, no ha sido desatendida por el mundo hispánico: con una actividad considerable, Eliseo Trenc, en particular, ha desarrollado desde la Universidad de Reims una fecunda labor de estudio y divulgación no sólo sobre las artes gráficas, sino también sobre las diversas corrientes del arte contemporáneo español, mientras que Louis Jambou, (musicología, París), ha propiciado la organización de un gran coloquio sobre Manuel de Falla, cuyas actas se acaban de publicar (París, 1999). Sin que sea necesario aquí resumir su ya rico catalógo de publicaciones, este breve repaso de la investigación francesa en materia hispánica quedaría muy incompleto si no se hiciera una mención aparte a la institución cuya función específica es precisamente desarrollar los estudios sobre España: la Casa de Velazquez, situada en Madrid pero bajo la autoridad del ministerio francés de Educación e Investigación. Dedicada a trabajos científicos y artísticos de muy diversa índole, consagra desde luego un esfuerzo particular al mundo español contemporáneo y por sus muros han pasado muchos de los mejores historiadores, geógrafos o hispanistas franceses, de modo que sus publicaciones son hoy de una imprescindible consulta ya. Paul Aubert, autor de un amplísimo pero parcilamente inédito estudio sobre intelectuales españoles y de una antología (Les Espagnols et l'Europe, Toulouse, 1992), fue durante muchos años responsable de la sección contemporánea, ha 
sido el coordinador de la organización de importantes coloquios, como los dedicados a Manuel Azaña et son temps (J.P. Amalric/ P. Aubert eds., Madrid, 1993) o a «Triunfo» en su época (P. Aubert ed., Madrid, 1995). Le sustituye hoy en esas funciones Benoît Pellistrandi, autor de una tesis sobre la Real Academia de la Historia y los académicos, con unas prometedoras actividades en este mismo campo.

Quien quiera disponer de datos más precisos sobre los diversos campos explorados por el actual hispanismo francés, puede consultar las contribuciones de Jean René Aymes y Jean François Botrel al número de la revista Ayer coordinado por Ismael Saz bajo el título España: la mirada del otro (1998), así como el balance general establecido por la Société des Hispanistes Français en las Actas de su XX Congreso, (Madrid, 1984), y publicado bajo el título La recherche hispanique en France (1962-1984). Espagne et Amérique Latine. De cualquier modo, como puede verse con este apresurado y excesivamente apretado resumen que aquí se ofrece, la investigación de los hispanistas franceses en relación con la España contemporánea es activa y productiva. En muchos casos, y como manera por lo demás de asegurar un buen nivel de todos estos trabajos, la colaboración con investigadores e instituciones españoles suele ser hoy la regla en coloquios o seminarios, pero también en publicaciones colectivas, aunque cabe subrayar el creciente papel que van jugando las diversas editoriales universitarias en la difusión (insuficiente) de estas investigaciones. No obstante, esta relación privilegiada y natural con los investigadores españoles no excluye los frecuentes encuentros y proyectos de colaboración con otros hispanistas venidos de horizontes más diversos. $\mathrm{Si}$, como se señalaba al principio, la situación general del hispanismo contemporaneista francés no incita al triunfalismo, dista mucho de ser improductivo, de modo que tampoco debe engendrar un pesimismo, que la calidad y la diversidad de muchas de las obras que se acaban de citar vendría a desmentir absolutamente. 